OPEN ACCESS

Edited by:

Blanca Fuentes,

University Hospital La Paz, Spain

Reviewed by:

Elena Palà,

Vall d'Hebron Research Institute

(NHIR), Spain

Jialing Liu,

University of California, San Francisco,

United States

*Correspondence:

Arnold Markus

markus.arnold@usz.ch

Specialty section:

This article was submitted to

Stroke,

a section of the journal

Frontiers in Neurology

Received: 01 November 2020

Accepted: 11 January 2021

Published: 25 February 2021

Citation:

Markus A, Valerie S and Mira K (2021)

Promising Biomarker Candidates for Cardioembolic Stroke Etiology. A Brief Narrative Review and Current Opinion.

Front. Neurol. 12:624930.

doi: 10.3389/fneur.2021.624930

\section{Promising Biomarker Candidates for Cardioembolic Stroke Etiology. A Brief Narrative Review and Current Opinion}

\author{
Arnold Markus*, Schütz Valerie and Katan Mira \\ Department of Neurology, University Hospital of Zurich, Zurich, Switzerland
}

Determining the cause of stroke is considered one of the main objectives in evaluating a stroke patient in clinical practice. However, ischemic stroke is a heterogeneous disorder and numerous underlying disorders are implicated in its pathogenesis. Although progress has been made in identifying individual stroke etiology, in many cases underlying mechanisms still remain elusive. Since secondary prevention strategies are tailored toward individual stroke mechanisms, patients whose stroke etiology is unknown may not receive optimal preventive treatment. Cardioembolic stroke is commonly defined as cerebral vessel occlusion by distant embolization arising from thrombus formation in the heart. It accounts for the main proportion of ischemic strokes, and its share to stroke etiology is likely to rise even further in future decades. However, it can be challenging to distinguish cardioembolism from other possible etiologies. As personalized medicine advances, stroke researchers' focus is increasingly drawn to etiology-associated biomarkers. They can provide deeper insight regarding specific stroke mechanisms and can help to unravel previously undetected pathologies. Furthermore, etiology-associated biomarkers could play an important role in guiding future stroke prevention strategies. To achieve this, broad validation of promising candidate biomarkers as well as their implementation in well-designed randomized clinical trials is necessary. This review focuses on the most-promising candidates for diagnosis of cardioembolic stroke. It discusses existing evidence for possible clinical applications of these biomarkers, addresses current challenges, and outlines future perspectives.

Keywords: biomarker, cardioembolic stroke, stroke etiology, ischemic stroke, secondary prevention

\section{INTRODUCTION}

Due to an aging world population and a global shift from communicable to non-communicable disease, lifetime risk for stroke and the absolute numbers of stroke survivors are increasing all over the world $(1,2)$. Ischemic stroke caused by an acute arterial occlusion is responsible for the majority of stroke events. In the acute phase of ischemic stroke, treatment strategies are focusing on the rapid reperfusion of affected tissue and the prevention of acute complications. Yet, patients who survive initial ischemic stroke share a high risk for disease recurrence. It is estimated that within five years at least one out of six stroke survivors is affected by a second event, underscoring the importance of optimal secondary prevention (3). Preventive strategies generally recommended for all patients 
include common elements of cardiovascular risk factor management like blood pressure control, cholesterol reduction, treatment of diabetes mellitus, and antiplatelet medication. However, given the heterogeneity of possible underlying stroke mechanisms, specific preventive interventions such as oral anticoagulation in patients with atrial fibrillation (AF) or carotid endarterectomy for symptomatic carotid artery stenosis are tailored toward an individual etiology. Thus, etiological classification is crucial for secondary prevention.

\section{CARDIOEMBOLIC STROKE ETIOLOGY}

Stroke caused by cardioembolism (CE) accounts for $\sim 20$ to $30 \%$ of ischemic strokes with higher incidence in older patients (4). Cardiac embolism is known to cause more severe strokes than other etiologies, and patients with CE strokes share high rates of both early and long-term recurrence $(5,6)$. Moreover, secular trends indicate that cardiac embolism accounts for an increasing share of strokes in high-income countries as the population ages and treatment of cardiovascular risk factors, especially hypertension and dyslipidemia leading to large-vessel atherosclerosis, improves with socioeconomic progress $(7,8)$. It is therefore estimated that the absolute numbers of $\mathrm{CE}$ strokes will continue to rise during the next decades (9).

AF represents the main identifiable risk factor for CE strokes, and treatment with oral anticoagulation can prevent up to $70 \%$ of recurring events in those patients. Less commonly identified causes of CE stroke include severe systolic heart failure, patent foramen ovale (PFO), prosthetic heart valves, recent myocardial infarction, intracardial masses, and endocarditis. For those, different secondary prevention strategies apply, but levels of evidence for optimal preventive strategies in these cases vary greatly [reviewed by Kamel et al. (4)]. Additionally, recent evidence indicates that the relationship between $\mathrm{AF}$ and CE stroke may be more complex than assumed. Under the current pathophysiological paradigm, blood stasis caused by arrhythmia leads to the formation of blood clots primarily in the left atrium (LA) from where they can embolize and cause distant brain-vessel occlusion. However, this paradigm is challenged by several findings: There was no clear temporal relationship between episodes of $\mathrm{AF}$ and occurrence of stroke in the ASSERT (10) and TRENDS (11) trials, rhythm control strategies were not able to lower stroke risk (12), and the number of cryptogenic stroke patients with newly diagnosed AF after extensive cardiac rhythm monitoring was unexpectedly low (13). Furthermore, it is well recognized that AF by itself is unlikely to be the sole cause for LA thrombogenesis, as the risk for stroke in AF patients is also highly influenced by the presence of common vascular risk factors (14). As a result, the concept of an underlying atrial myopathy as a possible source of cardiac embolism emerged. A diseased LA is histologically and functionally characterized by inflammation, endothelial dysfunction, fibrosis, contractile dysfunction, or structural derangement (15). These risk factors significantly contribute to a prothrombogenic microenvironment, favoring the possibility of thrombus formation and embolization. Therefore, stroke might occur even prior to manifestation of AF, and administration of anticoagulants could be beneficial at this stage (16). Yet, no clear definition of atrial myopathy exists and it remains to be determined how to correctly select patients at high risk for future $\mathrm{CE}$ stroke that may benefit from early systemic anticoagulation.

\section{LIMITATION OF CURRENT STROKE CLASSIFICATION SYSTEMS}

To date, there is no gold standard for the determination of CE stroke etiology. The identification of a high-risk cardiac source of embolism in the absence of significant arterial disease therefore remains the cornerstone of diagnosis. Attempting to standardize categorization, several classification systems are in use. The most widely accepted tool remains the Trial of Org 10172 in the Acute Stroke Treatment (TOAST) classification system developed in the 1990s (17). It uses diagnostic information from clinical workup to categorize stroke into five etiological categories: (1) large-vessel atherosclerosis, (2) cardioembolism, (3) small vessel disease, (4) other identifiable causes, and (5) stroke of "undetermined" etiology. The latest of the categories is considered the most heterogeneous group as it includes not only cases with lack of evidence for any predefined cause but also cases with incomplete evaluation and evidence for competing plausible causes. The TOAST classification has only moderate inter-examiner reliability $(18,19)$. Further, as etiological stroke evaluation advances by an increasing use of vascular imaging and long-term cardiac rhythm monitoring, the share of patients with a combination of vascular, cardiac, and other abnormal findings continually rise, inflating the proportion of "undertermined" etiologies by competing evidence. Therefore, up to $30 \%$ of strokes must be classified as "of undetermined source" (6) according to the TOAST classification. In an attempt to overcome these problems, a more sophisticated extension of the TOAST classification, the Causative Classification of Stroke (CCS), was developed. It incorporates levels of confidence for specific etiologies to successfully minimize classification of "undetermined etiology" $(20,21)$.

However, a different problem persists: stroke etiology can change over time. Even if the most likely cause of a stroke is classified non-cardioembolic, patients can still be affected by a CE stroke in the future. This is especially relevant, since the most common stroke mechanisms share common vascular risk factors by various extents. Therefore, adequately estimating the risk for a future stroke event and its etiology is equally important to correctly identify stroke mechanisms, especially for the long-term prophylaxis. Despite being more complicated and less commonly used in clinical practice, the 2013 revised phenotypic ASCOD classification system resembles this medical reasoning better (22). The ASCOD classification system describes all current pathologies that could potentially lead to an ischemic stroke in a given patient. It therefore captures the overlap between possible etiologies and weights the potential causal relationship in regard to the preceding stroke event (23). It does not determine a final stroke etiology per se but appreciates future stroke risk while inter-examiner reliability remains high 
$(24,25)$. Unfortunately, the ASCOD classification does not serve well as a tool for clinical decision making, due to its more descriptive character. Several other classification systems exist [ASCO, SPARKLE, CISS, KOREAN-TOAST; reviewed by Radu et al. (26)]. Occasional clinical use and lack of supporting data impede in-depth evaluation.

In addition to the aforementioned classification systems, the concept of embolic stroke of undetermined etiology (ESUS) was developed in 2014. ESUS defines a subset of patients with cryptogenic stroke with a non-lacunar stroke based on infarct topography and sufficient diagnostic workup to exclude the presence of a high-risk cardioembolic source or occlusive atherosclerosis (27). The concept was specifically designed to meet the operational criteria necessary for the conduct of randomized secondary prevention trials. However, after the failure of two large clinical trials in demonstrating any benefit of oral anticoagulation in ESUS patients $(28,29)$, the practical usefulness of the concept has recently been called into question.

\section{BIOMARKERS OF CARDIOEMBOLIC STROKE ETIOLOGY}

Biomarkers of CE-stroke etiology include parameters from cerebral imaging, electrocardiography, echocardiography, advanced cardiac imaging, and blood-based markers. To date, possible clinical applications are mainly risk stratification and acceleration of etiological classification, consequently accelerating optimal treatment. In the presence of competing evidence, biomarkers could increase the level of certainty for a causal relationship of a specific etiology. In cryptogenic strokes (with no evidence for a specific etiology), biomarkers could justify a more extensive workup [e.g., by selecting patients for prolonged cardiac monitoring (PCM)]. Most importantly, some biomarkers have been implemented in the design of randomized secondary prevention trials aiming to characterize high-risk subpopulations for CE stroke (e.g., patients with presumed atrial myopathy). Consequently, biomarkers have the potential to support decision making in future secondary stroke prevention. Table 1 gives an overview on potential biomarkers for CE stroke etiology.

\section{BLOOD-BASED BIOMARKERS}

Blood-based biomarkers share advantages over other types of biomarkers: They are rapidly measurable, they are cheaper compared to imaging or hands-on examinations, and-if possible confounders and demographic adjusted cutoffs are establishedtheir interpretation is examiner-independent and does not require specific training. To date, blood-based biomarkers are not routinely measured in stroke care and due to a substantial overlap in the pathophysiology of possible stroke mechanisms and shared risk factors, yet no single marker can perfectly distinguish between CE stroke and other etiologies. However, they can still add valuable information for both clinicians and researchers.

\section{BLOOD-BASED BIOMARKERS OF MYOCARDIAL STRESS}

Blood biomarkers of myocardial stress may add information on subclinical cardiac pathologies, e.g., the presence of underlying atrial myopathy, systolic heart failure, or subclinical AF.

Natriuretic peptides, namely, atrial natriuretic peptide (ANP) and brain natriuretic peptide (BNP) as well as their cleaved byproducts MRproANP and NTproBNP, belong to the most widely studied blood biomarkers to distinguish $\mathrm{CE}$ from non-CE stroke. For BNP and NT-proBNP, individual patient-pooled data metaanalysis (including data from 23 studies, 2834 patients) (30) as well as literature-based meta-analysis (including data from 16 studies, 2,958 patients) (31) provides compelling evidence for a consistent association with CE stroke etiology. This association was shown to be independent of demographic variables and stroke severity, which is important due to the association of CE etiology with more severe strokes. While less extensively studied, several studies evaluating the role of MR-proANP as a biomarker of CE stroke suggest at least similar associations $(34,35)$. MR-proANp was further shown to be associated with incidence of CE stroke but not with incidence LAA or SVD stroke (68). For ANP, only preliminary evidence exists. Having an ultra-short half-life, its usefulness in clinical practice is questionable (69). Additionally, for both NT-proBNP and MR-proBNP, it has been shown that the association with CEstroke etiology remains stable within the acute phase of stroke $(70,71)$. This is relevant because time-points of measurement can substantially influence the diagnostic utility of a biomarker, especially in hyperacute diseases such as ischemic stroke. While the evidence from individual studies and meta-analysis strongly support the role of natriuretic peptide analysis for etiological stroke classification, there is no universal agreement on optimal discriminatory cutoffs or the preferenced marker for clinical use. Meta-analysis of studies comparing NT-proBNP vs. BNP showed closely equivalent overall diagnostic accuracies (72). In one study that directly compared BNP and NT-proBNP in cryptogenic stroke patients, a higher specificity of BNP for the detection of AF was demonstrated (73). A direct comparison between brain natriuretic peptides and MRproANP is however still lacking.

In regard to a possible clinical application, indirect evidence supporting a role of natriuretic peptides in the selection of patients for oral anticoagulation arose from post hoc analysis of the WARSS trial. This was a randomized trial comparing warfarin and aspirin for the prevention of recurrent stroke in patients with presumed non-CE stroke (74). Among 1028 patients, those with plasma NT-proBNP concentrations above the 95th percentile $(>750 \mathrm{pg} / \mathrm{mL}$ ) had a significant reduction in the composite endpoint of stroke or death when being anti-coagulated with warfarin, compared to patients with NT-proBNP levels $\leq 750$ $\mathrm{pg} / \mathrm{mL}$ (32). These findings suggest that elevated NT-proBNP concentrations may identify a subgroup of patients with occult cardioembolic stroke mechanism (e.g., undiagnosed AF, atrial myopathy, or subclinical systolic heart failure), who could benefit from oral anticoagulation. 
TABLE 1 | Summary of potential cardioembolic stroke biomarkers and levels of evidence.

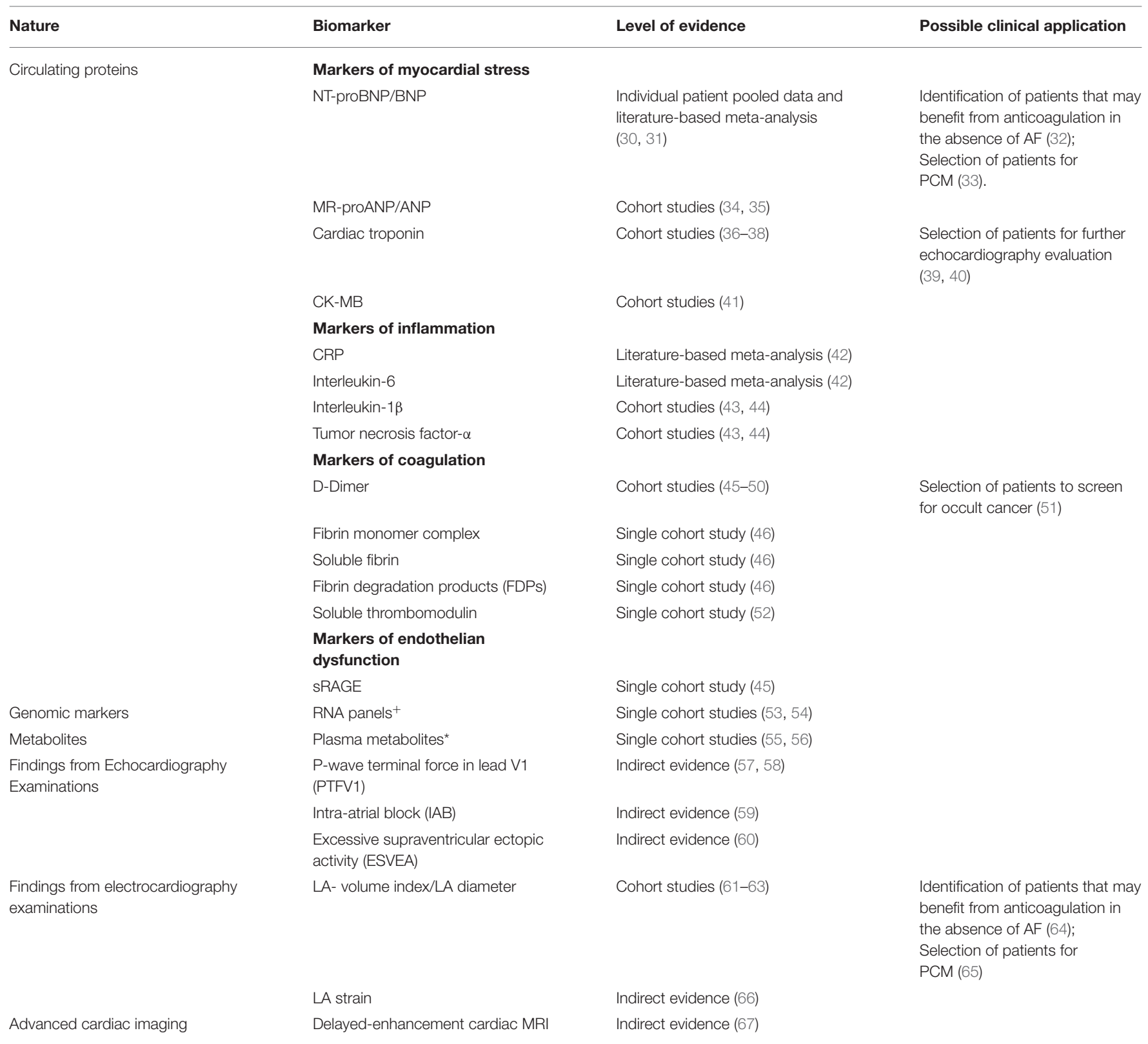

+40 gene and 23 gene panel; *free fatty acids; tricarboxylic acid metabolites-succinate, $\alpha$-ketoglutarate, malate.

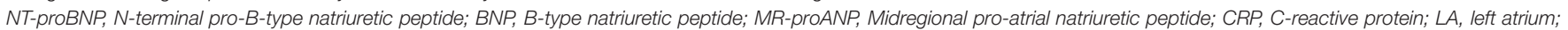
$P C M$, prolonged cardiac monitoring; sRAGE, soluble receptor for advanced glycation end products.

More recently, the investigators of the Find-AFRANDOMIZED trial showed that in patients over 60 years BNP levels can help to identify individuals in whom PCM is particularly efficacious to detect previously undiagnosed AF (33). These results support a clinical application of natriuretic peptides in risk stratification for PCM.

Evidence for the role of cardiac troponins and CK-MB in regard to classification of stroke etiology is more limited. Associations between positive troponin levels and CE stroke have been repeatedly found during the acute phase in single cohort studies $(36,37,75)$. It has also been shown that elevated troponin levels may improve the yield of abnormal echocardiography findings such as the presence of intracardiac thrombus, valvular disease, low ejection fraction, and akinetic wall segments. Therefore, troponin could be useful in selecting patients for further cardiac examinations $(39,40)$. However, a most recent substudy of the NAVIGATE-ESUS trial showed that high-sensitivity cardiac troponin $\mathrm{T}$ (hs-cTnT) was associated with increased rates of cardiovascular event but did not find any evidence supporting anticoagulation in these patients. This 
indicates that hs-cTnT is not useful to guide management of anticoagulation (76). Only limited evidence exists for the association of CK-MB with cardioembolism hindering any firm conclusions yet $(41,77)$.

\section{BLOOD-BASED BIOMARKERS OF INFLAMMATION}

Although markers of systemic inflammation such as CRP (C-reactive protein) and pro-inflammatory cytokines [e.g., Interleukin-6 (IL-6), Interleukin-1 $\beta$ (IL-1 $\beta$ ), and tumor-necrosis factor-alpha $(\mathrm{TNF} \alpha)$ ] have been mainly evaluated in regard to the diagnosis of large-artery atherosclerosis, growing evidence suggests a prominent role of systemic inflammation in the pathophysiology of $\mathrm{AF}$ (78) and the prothrombotic state in AF patients (79). Thus, inflammatory biomarkers may also be helpful in the diagnosis of CE stroke. In a 2017 meta-analysis (including 14 studies, 2,751 patients), CRP was significantly higher in CE strokes compared to non-CE strokes (42). However, no difference was found between CE stroke and LAA stroke alone. A possible explanation for this might be the involvement of inflammation in the underlying pathophysiology of both etiologies that limits the accuracy of CRP as an etiological biomarker. Evidence for inflammatory cytokines (e.g., IL-6, IL-1 $\beta$, and $\mathrm{TNF} \alpha$ ) is even more conflicting. While smaller studies have found higher levels of all three cytokines in CE stroke patients $(43,44)$, other studies could not find significant differences (80, 81). A 2017 meta-analysis on IL-6 (4 studies, 419 patients) could only confirm significantly higher levels in CEstroke patients compared to lacunar strokes but not to non-CE strokes combined (42). Furthermore, positive associations were not adjusted for stroke severity; thus, higher cytokine levels in CE stroke could be also explained by larger infarcts prompting more severe immunoreaction.

\section{BLOOD-BASED BIOMARKERS OF COAGULATION}

D-dimer, a degradation product of cross-linked fibrin, is formed during activation of the coagulation system. In CE stroke, it is hypothesized that $\mathrm{D}$-dimer levels reflect the formation of fibrin-rich thrombus in the left atrium. Contrarily, thrombi originating from large arteries are believed to be mostly plateletrich and therefore only promote a mild D-dimer increase (82). The association of higher levels of D-dimer with CE stroke etiology when measured during the acute phase $(<48 \mathrm{~h})$ has been repeatedly shown in individual studies (45-50). Further evidence indicates that the discriminatory ability may increase when D-dimers are measured ultra-early (3-6h) after symptom onset (83). Still, a positive association of D-dimer levels with CE stroke seems to remain stable beyond the acute phase (50). A major limitation of D-dimers, however, is their low specificity for a specific underlying pathophysiology. D-dimers are regularly elevated in many different thrombotic diseases but also in other systemic diseases. Some of the latter (e.g., systemic cancer, deep vein thrombosis in the presence of PFO or acute aortic dissection) are themselves associated with stroke. High D-dimer levels combined with typical DWI-lesion patterns in cryptogenic stroke patients may therefore play a role in the diagnosis of embolic stroke in the presence of occult cancer (84).

\section{OTHER CIRCULATING PROTEINS}

Although this review focuses on the most promising biomarkers that have proven consistent associations in multiple evaluations, it is to mention that preliminary data exists for a variety of other circulating proteins (also summarized in Table 1). However, the single-study nature of the existing evidence or conflicting results from different studies hinder any firm evaluation of their clinical usefulness yet. Further, recent advantages in proteomic studies may facilitate the discovery of novel potential biomarkers in upcoming decades.

\section{GENOMIC, TRANSCRIPTOMIC, AND METABOLIC MARKERS OF CARDIOEMBOLIC STROKE}

Little research has been done on possible genetic and metabolic markers of CE stroke. However, advances in high-throughput technologies in recent decades have provided researchers with new opportunities for biomarker discovery (85). Much recently, it was demonstrated that genetic risk variants associated with AF were also associated with CE stroke when combined in a polygenetic risk score (86). Further transcriptomics studies focusing on circulating RNAs in peripheral blood of stroke patients have shown promising results (87). In a pilot study, it was shown that a minimum of 23 genes was able to differentiate CE from LAA stroke with $>95 \%$ sensitivity and specificity (53). In a different study, a 40-gene profile differentiated CE stroke from large-vessel stroke with $>95 \%$ sensitivity and specificity (54). A separate 37-gene profile differentiated cardioembolic stroke due to AF from non-AF causes with $>90 \%$ sensitivity and specificity. Functional analysis of the genes involved highlighted a difference in the inflammatory response by various stroke subtypes. Confirmation in larger cohorts may thus inspire the development of PCR-based blood tests in the future. Only few studies have been conducted to examine whether metabolites can be used to differentiate stroke subtypes. It has been shown that levels of free fatty acids were $\sim 1.5$ fold higher in CE stroke compared to other subtypes (55). In a different study, levels of the tricarboxylic acid metabolites succinate, $\alpha$-ketoglutarate, and malate were associated with CE stroke. Interestingly, all three metabolites were also associated with subclinical atrial dysfunction (56). Whether these observations may be helpful to guide secondary prophylactic treatment remains to be determined.

\section{ELECTROCARDIOGRAPHICAL MARKERS}

Electrocardiographical (ECG) markers may similarly reveal subclinical cardiac pathologies. For etiological classification, possible markers focus mainly on abnormalities of the cardiac atria, as the left atrium is considered the main source of thrombus 
formation both, in the presence and absence of AF. P-wave terminal force in lead V1 (PTFV1) is an established marker of left atrial abnormality and was found to be an independent predictor of incident ischemic stroke as well as incident AF in meta-analysis $(88,89)$. While small studies have failed to provide direct evidence that PTFV1 can distinguish between etiologies in adult stroke patients (90), an association of PTFV1 with CE-stroke was seen in the Helsinki Young Stroke Registry reporting on ischemic strokes in patients aged 15 to 49 years (91). Further, indirect evidence from longitudinal-cohort studies supports an association with CE stroke etiology in adults: In a case-cohort analysis of the Northern Manhattan Study, the association of PTFV1 with the incidence of stroke was limited to $\mathrm{CE}$ and undetermined stroke. No association was found with non-CE stroke subtypes (57). Similarly, the atherosclerosis risk in communities study could demonstrate an association with nonlacunar but not with lacunar strokes (58). In both studies, the association was independent of the presence of AF; thus, PTFV1 may be a marker identifying underlying atrial myopathy as it is linked to atrial fibrosis. Further, in patients with embolic stroke of undetermined source (ESUS), increased PTFV1 was inversely associated with unstable extracranial sub-stenotic atherosclerosis as a potential cause of unrecognized LAA-associated stroke (92). Conflicting evidence exists in regard to the predictive value of PTFV1 for newly diagnosed AF after stroke $(93,94)$. Another possible ECG marker of cardiac embolism is the presence of interatrial block (IAB) or excessive supraventricular ectopic activity (ESVEA). In a retrospective single-center study, IAB has been significantly more prevalent in CE stroke compared to non$\mathrm{CE}$ stroke. Interestingly, IAB was also found to be associated with CE stroke in patients with sinus rhythm (59). In ESUS patients, $\mathrm{IAB}$ was associated with the diagnosis of subclinical $\mathrm{AF}$ and stroke recurrence $(95,96)$. ESVEA [defined as 30 premature atrial contractions (PACs) per hour daily, or any runs of $\geq 20$ PACs] was found to be associated with an increased risk of stroke in a longterm follow-up, independent of AF $(97,98)$. In a different study, the association of PACs with incidence stroke was limited to nonlacunar stroke (99). Further retrospective data showed that the number of PACs was higher in CE stroke and cryptogenic stroke compared to non-cardioembolic stroke (60).

In conclusion, preliminary evidence strongly supports a possible role of ECG parameters for etiological stroke classification. However, further studies are required to confirm this association and unravel possible clinical implications.

\section{MARKERS FROM ECHOCARDIOGRAPHY AND ADVANCED CARDIAC IMAGING}

Transthoracic and transesophageal echocardiography, cardiovascular computer tomography (cvCT), and cardiac magnetic resonance imaging (CMR) may reveal previously undetected sources of cardioembolism during stroke workup, e.g., LA thrombus, ventricular thrombus, intracardial masses, aortic arch atheroma, and PFO (100, 101). Despite that, cardiac imaging is useful to provide volumetric and functional assessment of the LA. LA volume index (LAVI) measurements by echocardiography have been shown to be associated with CE-stroke etiology (61-63). In line with that, moderate to severe LA enlargement, assessed by LA diameter, has also been found to be associated with recurrent cardioembolic/cryptogenic stroke risk, but not with total recurrent stroke risk in the Northern Manhattan Stroke Study (102). Most recently, another study was able to demonstrate that left atrial diameter above $40 \mathrm{~mm}$, may be useful to select patients for PCM (65). Furthermore, LA diameter was also associated with stroke recurrence in AF patients (103). Indirect evidence of a beneficial effect of oral anticoagulation was obtained in a secondary analysis of the NAVIGATE-ESUS trial: A subgroup of patients with moderate or severe LA enlargement treated with rivaroxaban showed a reduced risk of recurrent stroke (64). More recently, speckle tracking echocardiography-derived evaluation of LA deformation (LA strain) has gained attention as a possible novel marker of LA dysfunctionality (104). In a pilot study, low LA strain was associated with higher detection rates of paroxysmal AF in cryptogenic stroke patients (66). This association has been confirmed by a different study when measures of LA strain were combined with NT-proBNP (105). Further, measures of LA strain were shown to be independently associated with stroke occurrence in AF patients (106). Therefore, LA measurements might be another promising tool contributing to management of stroke preventive strategies.

The gold standard for the evaluation of LA enlargement remains CMR as it allows for $3 \mathrm{D}$ reconstruction as well LA hemodynamics (107, 108). Delayed-enhancement CMR (DE-CMR) provides a noninvasive way to characterize and quantify LA fibrosis in the general population, including individuals without known structural heart disease or AF (109). Retrospective multicenter studies including patients with AF have been able to show that DE-CMR was independently associated with a history of stroke (110) and future cerebrovascular events during follow-up (111). Patients with undetermined stroke had similar rates of LA fibrosis compared to patients with CE stroke, but higher rates compared to patients with other specific causes (67). This suggests presence of subclinical atrial disease in those patients. Comparable results were seen in ESUS patients. They showed similar rates of LA fibrosis compared to AF patients, but higher rates compared to healthy controls (112). Thus, LA fibrosis assessed by CMR could also be a promising marker for identifying underlying atrial myopathy and corresponding cardioembolic stroke risk in the future. However, further prospective studies need to investigate if DE-CMR is associated with risk of stroke in patients without AF before clinical trials may evaluate a benefit of anticoagulation in this patient population.

\section{FUTURE PERSPECTIVES}

Since the failure of the NAVIGATE-ESUS and RESPECT-ESUS trials to demonstrate a benefit of oral anticoagulation in patients with ESUS, optimal secondary prevention still remains elusive in a significant amount of patients. A more rigorous etiological workup may lead to the identification of more patients with 
competing etiological factors [like it has been seen in the NAVIGATE ESUS trial (113)]. Thus, it became obvious that optimal treatment has to be even more suited to individualized patient risk in regard to future cerebrovascular events.

Biomarkers add relevant information for this endeavor, specifically CE biomarkers alone or incorporated into validated risk scores, could guide clinicians selecting patients for more excessive workup (e.g., PCM). Examples for existing risk scores are the STAF, iPAB, and ASAS scores (114-116). They incorporate levels of BNP or presence of LA enlargement into clinical scores to predict AF after cerebrovascular events. This may increase the yield of positive PCM findings. Yet, external validation and cost effectiveness studies are pending. These studies are crucial to define adequate risk thresholds for patient selection. More importantly, biomarkers could have the potential to guide decision over secondary prevention strategies as indirect evidence already suggests. However, to pave the road to clinical application, the inherent shortcomings of etiological classification systems need to be overcome by the conduction of well-designed randomized trials.

Three trials that incorporate biomarkers to define target populations are currently enrolling: In the US, The Atrial Cardiopathy and Antithrombotic Drugs in Prevention After Cryptogenic Stroke (ARCADIA; NCT03192215) randomized trial evaluates apixaban compared to aspirin in ESUS patients with presumed atrial myopathy (defined by

\section{REFERENCES}

1. GBD 2016 Stroke Collaborators. Global, regional, and national burden of stroke, 1990-2016: a systematic analysis for the global burden of disease study 2016. Lancet Neurol. (2019) 18:439-58. doi: 10.1016/S1474-4422(19)30034-1

2. The GBD 2016 Lifetime Risk of Stroke Collaborators, Feigin VL, Nguyen G, Cercy K, Johnson CO, Alam T, et al. Global, regional, and countrySpecific lifetime risks of stroke, 1990 and 2016. N Engl J Med. (2018) 379:2429-37. doi: 10.1056/NEJMoa1804492

3. Mohan KM, Wolfe CD, Rudd AG, Heuschmann PU, KolominskyRabas PL, Grieve AP. Risk and cumulative risk of stroke recurrence: a systematic review and meta-analysis. Stroke. (2011) 42:1489-94. doi: 10.1161/STROKEAHA.110.602615

4. Kamel H Healey JS. Cardioembolic stroke. Circ Res. (2017) 120:51426. doi: 10.1161/CIRCRESAHA.116.308407

5. Lin HJ, Wolf PA, Kelly-Hayes M, Beiser AS, Kase CS, Benjamin EJ, et al. Stroke severity in atrial fibrillation. The Framingham study. Stroke. (1996) 27:1760-4. doi: 10.1161/01.str.27.10.1760

6. Kolominsky-Rabas PL, Weber M, Gefeller O, Neundoerfer B, Heuschmann PU. Epidemiology of ischemic stroke subtypes according to tOAST criteria: incidence, recurrence, and long-term survival in ischemic stroke subtypes: a population-based study. Stroke. (2001) 32:273540. doi: 10.1161/hs1201.100209

7. Yiin GSC, Li L, Bejot Y, Rothwell PM. Time trends in atrial fibrillationassociated stroke and premorbid anticoagulation. Stroke. (2018) 50:21-7. doi: 10.1161/STROKEAHA.118.022249

8. Bogiatzi C, Hackam DG, McLeod AI, Spence JD. Secular trends in ischemic stroke subtypes and stroke risk factors. Stroke. (2014) 45:320813. doi: 10.1161/STROKEAHA.114.006536

9. Yiin GS, Howard DP, Paul NL, Li L, Luengo-Fernandez R, Bull LM, et al. Age-specific incidence, outcome, cost, and projected future burden of atrial fibrillation-related embolic vascular events: a population-based study. Circulation. (2014) 130:1236-44. doi: 10.1161/CIRCULATIONAHA.114.010942
NTproANP levels $>250 \mathrm{pg} / \mathrm{ml}$, PTFV1 $>5000 \mathrm{~V} \times \mathrm{ms}$ or LA enlargement defined as LA diameter index $\geq 3 \mathrm{~cm} / \mathrm{m}^{2}$ on echocardiography). In Europe, the Midregional Proatrial Natriuretic Peptide to guide Secondary Stroke Prevention (MOSES; NCT03961334) randomized trial evaluates oral anticoagulation vs. antiplatelet therapy in patients without previous AF (selected by a MRproANP levels $\geq 200 \mathrm{pg} / \mathrm{l}$ ) and the Apixaban for Treatment of Embolic Stroke of Undetermined Source (ATTICUS; NCT02427126) trial is evaluating apixaban compared to aspirin in ESUS patients with at least one nonmajor risk factor for cardioembolism including possible echoand electrocardiography markers such as LA size $>45 \mathrm{~mm}$ in parasternal axis, reduced LAA flow velocity $\leq 0.2 \mathrm{~m} / \mathrm{s}$, spontaneous LAA contrast, atrial high rate episodes, and PFO. If completed successfully, data from these trials not only could provide compelling evidence for the concept of atrial myopathy but also may prove the benefit of biomarker-guided therapy.

Thus, biomarkers of CE-stroke etiology could ultimately evolve as a cornerstone in decision making regarding secondary stroke prevention.

\section{AUTHOR CONTRIBUTIONS}

AM wrote the first draft of the manuscript. SV and KM wrote sections of the manuscript. All authors contributed to manuscript revision, read, and approved the submitted version.

10. Brambatti M, Connolly SJ, Gold MR, Morillo CA, Capucci A, Muto C, et al. Temporal relationship between subclinical atrial fibrillation and embolic events. Circulation. (2014) 129:20949. doi: 10.1161/CIRCULATIONAHA.113.007825

11. Daoud EG, Glotzer TV, Wyse DG, Ezekowitz MD, Hilker C, Koehler J, et al. Temporal relationship of atrial tachyarrhythmias, cerebrovascular events, and systemic emboli based on stored device data: a subgroup analysis of tRENDS. Heart Rhythm. (2011) 8:1416-23. doi: 10.1016/j.hrthm.2011. 04.022

12. Van Gelder IC, Hagens VE, Bosker HA, Kingma JH, Kamp O, Kingma $\mathrm{T}$, et al. A comparison of rate control and rhythm control in patients with recurrent persistent atrial fibrillation. N Engl J Med. (2002) 347:183440. doi: 10.1056/NEJMoa021375

13. Sanna T, Diener HC, Passman RS, Di Lazzaro V, Bernstein RA, Morillo CA, et al. Cryptogenic stroke and underlying atrial fibrillation. $N$ Engl J Med. (2014) 370:2478-86. doi: 10.1056/NEJMoa1313600

14. Lip GY, Nieuwlaat R, Pisters R, Lane DA, Crijns HJ. Refining clinical risk stratification for predicting stroke and thromboembolism in atrial fibrillation using a novel risk factor-Based approach the euro heart survey on atrial fibrillation. Chest. (2010) 137:263-72. doi: 10.1378/chest. 09-1584

15. Kamel H, Okin PM, Elkind MS, Iadecola C. Atrial fibrillation and mechanisms of stroke: time for a new model. Stroke. (2016) 47:895900. doi: 10.1161/STROKEAHA.115.012004

16. Shen MJ, Arora R Jalife J. Atrial myopathy. JACC Basic Transl Sci. (2019) 4:640-54. doi: 10.1016/j.jacbts.2019.05.005

17. Adams HP Jr, Woolson RF, Clarke WR, Davis PH, Bendixen BH, Love BB, et al. Design of the trial of org 10172 in acute stroke treatment (TOAST). Control Clin Trials. (1997) 18:358-77. doi: 10.1016/s0197-2456(97)00012-3

18. Meschia JF, Barrett KM, Chukwudelunzu F, Brown WM, Case $\mathrm{LD}$, Kissela $\mathrm{BM}$, et al. Interobserver agreement in the trial of org 10172 in acute stroke treatment classification of stroke based on retrospective medical record review. J Stroke Cerebrovasc Dis. (2006) 15:266-72. doi: 10.1016/j.jstrokecerebrovasdis.2006.07.001 
19. Selvarajah JR, Glaves M, Wainwright J, Jha A, Vail A, Tyrrell PJ. Classification of minor stroke: intra- and inter-observer reliability. Cerebrovasc Dis. (2009) 27:209-14. doi: 10.1159/000196817

20. Ay H, Benner T, Arsava EM, Furie KL, Singhal AB, Jensen MB, et al. A computerized algorithm for etiologic classification of ischemic stroke: the causative classification of stroke system. Stroke. (2007) 38:297984. doi: 10.1161/STROKEAHA.107.490896

21. Ay H, Furie KL, Singhal A, Smith WS, Sorensen AG, Koroshetz WJ. An evidence-based causative classification system for acute ischemic stroke. Ann Neurol. (2005) 58:688-97. doi: 10.1002/ana.20617

22. Amarenco P, Bogousslavsky J, Caplan LR, Donnan GA, Wolf ME, Hennerici MG. The aSCOD phenotyping of ischemic stroke (Updated aSCO phenotyping). Cerebrovasc Dis. (2013) 36:1-5. doi: 10.1159/000352050

23. Sirimarco G, Lavallée PC, Labreuche J, Meseguer E, Cabrejo L, Guidoux C, et al. Overlap of diseases underlying ischemic stroke: the aSCOD phenotyping. Stroke. (2013) 44:242733. doi: 10.1161/STROKEAHA.113.001363

24. Chen N, Zhou M, Wang Y, Wang H, Yang M, Guo J, et al. Inter-rater reliability of the A-S-C-O classification system for ischemic stroke. J Clin Neurosci. (2013) 20:410-2. doi: 10.1016/j.jocn.2012.01.059

25. Wolf ME, Sauer T, Alonso A, Hennerici MG. Comparison of the new aSCO classification with the tOAST classification in a population with acute ischemic stroke. J Neurol. (2012) 259:1284-9. doi: 10.1007/s00415-011-6325-1

26. Radu RA, Terecoasă EO, Băjenaru OA, Tiu C. Etiologic classification of ischemic stroke: where do we stand? Clin Neurol Neurosur. (2017) 159:93106. doi: 10.1016/j.clineuro.2017.05.019

27. Hart RG, Diener HC, Coutts SB, Easton JD, Granger CB. Embolic strokes of undetermined source: the case for a new clinical construct. Lancet Neurol. (2014) 13:429-38. doi: 10.1016/S1474-4422(13)70310-7

28. Diener HC, Sacco RL, Easton JD, Granger CB, Bernstein RA, Uchiyama S, et al. Dabigatran for prevention of stroke after embolic stroke of undetermined source. $N$ Engl J Med. (2019) 380:1906-17. doi: 10.1056/NEJMoa1813959

29. Girgis M Jelaidan I. Rivaroxaban for stroke prevention after embolic stroke of undetermined source. $N$ Engl J Med. (2018) 379:986. doi: 10.1056/NEJMc1809065

30. Llombart V, Antolin-Fontes A, Bustamante A, Giralt D, Rost NS, Furie $\mathrm{K}$, et al. B-type natriuretic peptides help in cardioembolic stroke diagnosis: pooled data meta-analysis. Stroke. (2015) 46:11871195. doi: 10.1161/STROKEAHA.114.008311

31. Yang HL, Lin YP, Long Y, Ma QL, Zhou C. Predicting cardioembolic stroke with the B-type natriuretic peptide test: a systematic review and meta-analysis. J Stroke Cerebrovasc Dis. (2014) 23:1882-9. doi: 10.1016/j.jstrokecerebrovasdis.2014.02.014

32. Longstreth WT, Kronmal RA, Thompson JL, Christenson RH, Levine SR, Gross R, et al. Amino terminal pro-B-type natriuretic peptide, secondary stroke prevention, and choice of antithrombotic therapy. Stroke. (2013) 44:714-9. doi: 10.1161/STROKEAHA.112.675942

33. Wasser $K$, Weber-Krüger M, Gröschel $S$, Uphaus T, Liman J, Hamann GF, et al. Brain natriuretic peptide and discovery of atrial fibrillation after stroke a Subanalysis of the find-AF(RANDOMISED) trial. Stroke. (2020) 51:395-401. doi: 10.1161/Strokeaha.119.026496

34. De Marchis GM, Schneider J, Weck A, Fluri F, Fladt J, Foerch C, et al. Midregional proatrial natriuretic peptide improves risk stratification after ischemic stroke. Neurology. (2018) 90:e455-e65. doi: 10.1212/WNL.0000000000004922

35. Katan M, Fluri F, Schuetz P, Morgenthaler NG, Zweifel C, Bingisser $\mathrm{R}$, et al. Midregional pro-atrial natriuretic peptide and outcome in patients with acute ischemic stroke. J Am Coll Cardiol. (2010) 56:104553. doi: $10.1016 /$ j.jacc.2010.02.071

36. Nisar T, Kamin S. Association of serum troponin obtained during stroke codes with cardioembolic strokes. J Stroke Cerebrovasc. (2020) 29:104527. doi: 10.1016/j.jstrokecerebrovasdis.2019.104527

37. Terceno M, Silva Y, Bashir S, Vera-Monge V, Bux M, Serena J. Troponin t Predicts cardioembolic aetiology and clinical outcome in undetermined ischaemic stroke in hyperacute phase. J Stroke Cerebrovasc. (2020) 29:104528. doi: 10.1016/j.jstrokecerebrovasdis.2019.104528
38. Yaghi S, Chang AD, Ricci BA, Jayaraman MV, McTaggart RA, Hemendinger $M$, et al. Early elevated troponin levels after ischemic stroke suggests a cardioembolic source. Stroke. (2018) 49:E24. doi: 10.1161/Str.0000000000000157

39. Wrigley P, Khoury J, Eckerle B, Alwell K, Moomaw CJ, Woo D, et al. Prevalence of positive troponin and echocardiogram findings and association with mortality in acute ischemic stroke. Stroke. (2017) 48:1226. doi: 10.1161/Strokeaha.116.014561

40. Yaghi S, Chang AD, Cutting S, Jayaraman M, McTaggart RA, Ricci BA, et al. Troponin improves the yield of transthoracic echocardiography in ischemic stroke patients of determined stroke subtype. Stroke. (2018) 49:2777-9. doi: 10.1161/Strokeaha.118.022477

41. Rodriguez-Yanez M, Sobrino T, Blanco M, de la Ossa NP, Brea D, RodriguezYanez R, et al. High serum levels of pro-brain natriuretic peptide (pro bNP) identify cardioembolic origin in undetermined stroke. Dis Markers. (2009) 26:189-95. doi: 10.1155/2009/351591

42. Piccardi B, Giralt D, Bustamante A, Llombart V, García-Berrocoso T, Inzitari $\mathrm{D}$, et al. Blood markers of inflammation and endothelial dysfunction in cardioembolic stroke: systematic review and meta-analysis. Biomarkers. (2017) 22:200-9. doi: 10.1080/1354750X.2017.1286689

43. Licata G, Tuttolomondo A, Di Raimondo D, Corrao S, Di Sciacca R, Pinto A. Immuno-inflammatory activation in acute cardio-embolic strokes in comparison with other subtypes of ischaemic stroke. Thromb Haemost. (2009) 101:929-37.

44. Tuttolomondo A, Di Sciacca R, Di Raimondo D, Serio AD, Aguanno G. Plasma levels of inflammatory and thrombotic/fibrinolytic markers in acute ischemic strokes: relationship with tOAST subtype, outcome and infarct site. J Neuroimmunol. (2009) 215:84-9. doi: 10.1016/j.jneuroim.2009. 06.019

45. Montaner J, Perea-Gainza M, Delgado P, Ribo M, Chacon P, Rosell A, et al. Etiologic diagnosis of ischemic stroke subtypes with plasma biomarkers. Stroke. (2008) 39:2280-7. doi: 10.1161/strokeaha.107.505354

46. Hirano K, Takashima S, Dougu N, Taguchi Y, Nukui T, Konishi $\mathrm{H}$, et al. Study of hemostatic biomarkers in acute ischemic stroke by clinical subtype. J Stroke Cerebrovasc. (2012) 21:404-10. doi: 10.1016/j.jstrokecerebrovasdis.2011.08.013

47. Alvarez-Perez FJ, Castelo-Branco M, Alvarez-Sabin J. Usefulness of measurement of fibrinogen, $d$-dimer, d-dimer/fibrinogen ratio, $c$ reactive protein and erythrocyte sedimentation rate to assess the pathophysiology and mechanism of ischaemic stroke. J Neurol Neurosur Ps. (2011) 82:98692. doi: 10.1136/jnnp.2010.230870

48. Zi WJ, Shuai J. Plasma d-Dimer levels are associated with stroke subtypes and infarction volume in patients with acute ischemic stroke. PLoS ONE. (2014) 9:e86465. doi: 10.1371/journal.pone.0086465

49. Tomich C, Liegey JS, Sagnier S, Olindo S, Poli M, Debruxelles $\mathrm{S}$, et al. Contribution of routine cardiac biological markers to the etiological workup of ischemic stroke. Am J Emerg Med. (2019) 37:1948. doi: 10.1016/j.ajem.2018.05.010

50. Ageno W, Finazzi S, Steidl L, Biotti MG, Mera V, Melzi D, et al. Plasma measurement of d-dimer levels for the early diagnosis of ischemic stroke subtypes. Arch Intern Med. (2002) 162:2589-93. doi: 10.1001/archinte.162.22.2589

51. Selvik HA, Bjerkreim AT, Thomassen L, aje-Andreassen U, Naess H, Kvistad CE. W. When to screen ischaemic stroke patients for cancer. Cerebrovasc Dis. (2018) 45:42-7. doi: 10.1159/000484668

52. Dharmasaroja P, Dharmasaroja PA, Sobhon P. Increased plasma soluble thrombomodulin levels in cardioembolic stroke. Clin Appl Thromb-Hem. (2012) 18:289-3. doi: 10.1177/1076029611432744

53. Xu H, Tang Y, Liu DZ, Ran R, Ander BP, Apperson M, et al. Gene expression in peripheral blood differs after cardioembolic compared with large-vessel atherosclerotic stroke: biomarkers for the etiology of ischemic stroke. J Cereb Blood Flow Metab. (2008) 28:1320-8. doi: 10.1038/jcbfm.2008.22

54. Jickling GC, Xu H, Stamova B, Ander BP, Zhan X, Tian Y, et al. Signatures of cardioembolic and large-vessel ischemic stroke. Ann Neurol. (2010) 68:68192. doi: 10.1002/ana.22187

55. Choi JY, Kim JS, Kim JH, Oh K, Koh SB, Seo WK. High free fatty acid level is associated with recurrent stroke in cardioembolic stroke patients. Neurology. (2014) 82:1142-8. doi: 10.1212/Wnl.0000000000000264 
56. Nelson SE, Ament Z, Wolcott Z, Gerszten RE, Kimberly WT. Succinate links atrial dysfunction and cardioembolic stroke. Neurology. (2019) 92:e802e10. doi: 10.1212/WNL.0000000000006957

57. Kamel H, Hunter M, Moon YP, Yaghi S, Cheung K, Di Tullio MR, et al. Electrocardiographic left atrial abnormality and risk of stroke: northern Manhattan study. Stroke. (2015) 46:3208-12. doi: 10.1161/STROKEAHA.115.009989

58. Kamel H, O'Neal WT, Okin PM, Loehr LR, Alonso A. Electrocardiographic left atrial abnormality and stroke subtype in the atherosclerosis risk in communities study. Ann Neurol. (2015) 78:670-8. doi: 10.1002/ana. 24482

59. Ariyarajah V, Puri P, Apiyasawat S, Spodick DH et al. Interatrial block: a novel risk factor for embolic stroke? Ann Noninvasive Electrocardiol. (2007) 12:15. doi: 10.1111/j.1542-474X.2007.00133.x

60. Todo K, Moriwaki H, Saito K, Naritomi H. Frequent premature atrial contractions in stroke of undetermined etiology. Eur Neurol. (2009) 61:2858. doi: $10.1159 / 000206853$

61. Shin HY, Jeong IH, Kang CK, Shin DJ, Park HM, Park KH, et al. Relation between left atrial enlargement and stroke subtypes in acute ischemic stroke patients. J Cerebrovasc Endovasc Neurosurg. (2013) 15:1316. doi: 10.7461/jcen.2013.15.3.131

62. Jordan K, Yaghi S, Poppas A, Chang AD, Grory BC, Cutting S, et al. Left atrial volume index is associated with cardioembolic stroke and atrial fibrillation detection after embolic stroke of undetermined source. Stroke. (2019) 50:1997-2001. doi: 10.1161/Strokeaha.119.025384

63. Kamel H, Okin PM, Merkler AE, Navi BB, Campion TR, Devereux RB, et al. Relationship between left atrial volume and ischemic stroke subtype. Ann Clin Transl Neur. (2019) 6:1480-6. doi: 10.1002/acn3.50841

64. Healey JS, Gladstone DJ, Swaminathan B, Eckstein J, Mundl H, Epstein $\mathrm{AE}$, et al. Recurrent stroke with rivaroxaban compared with aspirin according to predictors of atrial fibrillation: secondary analysis of the nAVIGATE eSUS randomized clinical trial. JAMA Neurol. (2019) 76:76473. doi: 10.1001/jamaneurol.2019.0617

65. Perlepe K, Sirimarco G, Strambo D, Eskandari A, Karagkiozi E, Vemmou A, et al. Left atrial diameter thresholds and new incident atrial fibrillation in embolic stroke of undetermined source. Eur J Intern Med. (2020) 75:3034. doi: 10.1016/j.ejim.2020.01.002

66. Pagola J, Gonzalez-Alujas T, Flores A, Muchada M, Rodriguez-Luna $\mathrm{D}$, Sero L, et al. Left atria strain is a surrogate marker for detection of atrial fibrillation in cryptogenic strokes. Stroke. (2014) 45:E164E6. doi: 10.1161/Strokeaha.114.005540

67. Fonseca AC, Alves P, Inacio N, Marto JP, Viana-Baptista M, Pinho EMT, et al. Patients with undetermined stroke have increased atrial fibrosis: a cardiac magnetic resonance imaging study. Stroke. (2018) 49:7347. doi: 10.1161/STROKEAHA.117.019641

68. Katan M, Moon YP, Paik MC, Mueller B, Huber A, Sacco RL, et al. Procalcitonin and midregional proatrial natriuretic peptide as markers of ischemic stroke: the northern manhattan study. Stroke. (2016) 47:17149. doi: 10.1161/STROKEAHA.115.011392

69. Shiroto H, Tomita H, Hagii J, Metoki N, Fujita A, Kamada T, et al. Impact of atrial natriuretic peptide value for predicting paroxysmal atrial fibrillation in ischemic stroke patients. J Stroke Cerebrovasc. (2017) 26:7728. doi: 10.1016/j.jstrokecerebrovasdis.2016.10.016

70. Fonseca AC, Matias JS, E Melo TP, Pires C, Geraldes R, Canhao P, et al. Time course of nT-proBNP levels after acute ischemic stroke. Acta Neurol Scand. (2013) 128:235-40. doi: 10.1111/ane.12112

71. Arnold M, Nakas C, Luft A, Christ-Crain M, Leichtle A, Katan M. Independent prognostic value of mRproANP (Midregional proatrial natriuretic peptide) levels in patients with stroke is unaltered over time. Stroke. (2020) 51:1873-5. doi: 10.1161/STROKEAHA.120.029333

72. Bai J, Sun H, Xie L, Zhu Y, Feng Y. Detection of cardioembolic stroke with b-type natriuretic peptide or n-terminal pro-BNP: a comparative diagnostic meta-analysis. Int $J$ Neurosci. (2018) 128:1100-8. doi: 10.1080/00207454.2017.1408612

73. Pala E, Pagola J, Juega J, Francisco-Pascual J, Bustamante A, Penalba A, et al. B-type natriuretic peptide over $\mathrm{N}$-terminal pro-brain natriuretic peptide to predict incident atrial fibrillation after cryptogenic stroke. Eur J Neurol. (2020) 28:540-7. doi: 10.1111/ene.14579
74. Mohr JP, Thompson JL, Lazar RM, Levin B, Sacco RL, Furie KL, et al. A comparison of warfarin and aspirin for the prevention of recurrent ischemic stroke. N Engl J Med. (2001) 345:1444-51. doi: 10.1056/NEJMoa011258

75. Yaghi S, Chang AD, Ricci BA, Jayaraman MV, McTaggart RA, Hemendinger $M$, et al. Early elevated troponin levels after ischemic stroke suggests a cardioembolic source. Stroke. (2018) 49:121-6. doi: 10.1161/Strokeaha.117.019395

76. Scheitz JF, Pare G, Pearce LA, Mundl H, Peacock WF, Czlonkowska A, et al. High-Sensitivity cardiac troponin $\mathrm{t}$ for risk stratification in patients with embolic stroke of undetermined source. Stroke. (2020) 51:238694. doi: 10.1161/STROKEAHA.120.029628

77. Santamarina E, Penalba A, García-Berrocoso T, Delgado P, Quintana M, González-Alujas T, et al. Biomarker level improves the diagnosis of embolic source in ischemic stroke of unknown origin. J Neurol. (2012) 259:253845. doi: 10.1007/s00415-012-6532-4

78. Boos CJ, Anderson RA Lip GYH. Is atrial fibrillation an inflammatory disorder? Eur Heart J. (2006) 27:136-49. doi: 10.1093/eurheartj/ehi645

79. Guo YT, Lip GYH Apostolakis S. Inflammation in atrial fibrillation. J Am Coll Cardiol. (2012) 60:2263-70. doi: 10.1016/j.jacc.2012.04.063

80. Nakase T, Yamazaki T, Ogura N, Suzuki A, Nagata K. The impact of inflammation on the pathogenesis and prognosis of ischemic stroke. J Neurol Sci. (2008) 271:104-9. doi: 10.1016/j.jns.2008.03.020

81. Purroy F, Suárez-Luis I, Mauri-Capdevila G, Cambray S, Farré J, Sanahuja J, et al. N- terminal pro- brain natriuretic peptide level determined at different times identifies transient ischaemic attack patients with atrial fibrillation. Eur J Neurol. (2014) 21:679-83. doi: 10.1111/ene.12222

82. Ohara T, Farhoudi M, Bang OY, Koga M, Demchuk AM. The emerging value of serum d-dimer measurement in the work-up and management of ischemic stroke. Int J Stroke. (2020) 15:122-31. doi: 10.1177/1747493019876538

83. Isenegger J, Meier N, Lammle B, Alberio L, Fischer U, Nedeltchev K, et al. DDimers predict stroke subtype when assessed early. Cerebrovasc Dis. (2010) 29:82-6. doi: 10.1159/000256652

84. Bang OY, Ovbiagele B, Kim JS. Evaluation of cryptogenic stroke with advanced diagnostic techniques. Stroke. (2014) 45:1186-94. doi: 10.1161/STROKEAHA.113.003720

85. Montaner J, Ramiro L, Simats A, Tiedt S, Makris K, Jickling GC, et al. Multilevel omics for the discovery of biomarkers and therapeutic targets for stroke. Nat Rev Neurol. (2020) 16:247-64. doi: 10.1038/s41582-020-0350-6

86. Pulit SL, Weng LC, McArdle PF, Trinquart L, Choi SH, Mitchell BD, et al. Atrial fibrillation genetic risk differentiates cardioembolic stroke from other stroke subtypes. Neurol Genet. (2018) 4:e293. doi: 10.1212/NXG.0000000000000293

87. García-Berrocoso T, Palà E, Consegal M, Piccardi B, Negro A, Gill N, et al. Cardioembolic ischemic stroke gene expression fingerprint in blood: a systematic review and verification analysis. Transl Stroke Res. (2020) 11:326-36. doi: 10.1007/s12975-019-00730-x

88. He J, Tse G, Korantzopoulos P, Letsas KP, Ali-Hasan-AlSaegh S, Kamel H, et al. P-Wave indices and risk of ischemic stroke: a Systematic review and meta-Analysis. Stroke. (2017) 48:2066-72. doi: 10.1161/STROKEAHA.117.017293

89. Huang Z, Zheng Z, Wu B, Tang L, Xie X, Dong R, et al. Predictive value of $\mathrm{p}$ wave terminal force in lead v1 for atrial fibrillation: a meta-analysis. Ann Noninvasive Electrocardiol. (2020) 25:e12739. doi: 10.1111/anec.12739

90. Kwon Y, McHugh S, Ghoreshi K, Lyons GR, Cho Y, Bilchick $\mathrm{KC}$, et al. Electrocardiographic left atrial abnormality in patients presenting with ischemic stroke. J Stroke Cerebrovasc Dis. (2020) 29:105086. doi: 10.1016/j.jstrokecerebrovasdis.2020.105086

91. Pirinen J, Putaala J, Aro AL, Surakka I, Haapaniemi A, Kaste M, et al. Resting 12-lead electrocardiogram reveals high-risk sources of cardioembolism in young adult ischemic stroke. Int J Cardiol. (2015) 198:196-200. doi: 10.1016/j.ijcard.2015.06.095

92. Lattanzi S, Cagnetti C, Pulcini A, Morelli M, Maffei S, Provinciali L, et al. The p-wave terminal force in embolic strokes of undetermined source. J Neurol Sci. (2017) 375:175-8. doi: 10.1016/j.jns.2017.01.063

93. Goda T, Sugiyama Y, Ohara N, Ikegami T, Watanabe K, Kobayashi J, et al. $\mathrm{P}$-Wave terminal force in lead v1 predicts paroxysmal atrial fibrillation in acute ischemic stroke. J Stroke Cerebrovasc Dis. (2017) 26:19125. doi: 10.1016/j.jstrokecerebrovasdis.2017.06.031 
94. Baturova MA, Sheldon SH, Carlson J, Brady PA, Lin G, Rabinstein AA, et al. Electrocardiographic and echocardiographic predictors of paroxysmal atrial fibrillation detected after ischemic stroke. BMC Cardiovasc Disord. (2016) 16:209. doi: 10.1186/s12872-016-0384-2

95. Jung M, Kim JS, Song JH, Kim JM, Park KY, Lee WS, et al. Usefulness of p Wave duration in embolic stroke of undetermined source. J Clin Med. (2020) 9:1134. doi: 10.3390/jcm9041134

96. Mendieta G, Guasch E, Weir D, Aristizabal D, Escobar-Robledo LA, Llull L, et al. Advanced interatrial block: a predictor of covert atrial fibrillation in embolic stroke of undetermined source. J Electrocardiol. (2020) 58:1138. doi: 10.1016/j.jelectrocard.2019.11.050

97. Larsen BS, Kumarathurai P, Falkenberg J, Nielsen OW, Sajadieh A. Excessive atrial ectopy and short atrial runs increase the risk of stroke beyond incident atrial fibrillation. J Am Coll Cardiol. (2015) 66:23241. doi: 10.1016/j.jacc.2015.05.018

98. Binici $Z$, Intzilakis $\mathrm{T}$, Nielsen OW, Kober $\mathrm{L}$, Sajadieh A. Excessive supraventricular ectopic activity and increased risk of atrial fibrillation and stroke. Circulation. (2010) 121:190411. doi: 10.1161/CIRCULATIONAHA.109.874982

99. O’Neal WT, Kamel H, Kleindorfer D, Judd SE, Howard G. Premature atrial contractions on the screening electrocardiogram and risk of ischemic stroke: the reasons for geographic and racial differences in stroke study. Neuroepidemiology. (2016) 47:53-8. doi: 10.1159/000448619

100. Pagán RJ, Parikh PP, Mergo PJ, Gerber TC, Mankad R, Freeman WD, et al. Emerging role of cardiovascular $\mathrm{cT}$ and $\mathrm{mRI}$ in the evaluation of stroke. AJR Am J Roentgenol. (2015) 204:269-80. doi: 10.2214/AJR.14.13051

101. Rustemli A, Bhatti TK Wolff SD. Evaluating cardiac sources of embolic stroke with mRI. Echocardiography. (2007) 24:301-8; discussion 308. doi: 10.1111/j.1540-8175.2007.00393.x

102. Yaghi S, Moon YP, Mora-McLaughlin C, Willey JZ, Cheung K, Di Tullio $\mathrm{MR}$, et al. Left atrial enlargement and stroke recurrence the northern manhattan stroke study. Stroke. (2015) 46:1488. doi: 10.1161/strokeaha.115. 008711

103. Ogata T, Matsuo R, Kiyuna F, Hata J, Ago T, Tsuboi Y, et al. Left atrial size and long-Term risk of recurrent stroke after acute ischemic stroke in patients with nonvalvular atrial fibrillation. J Am Heart Assoc. (2017) 6:6402. doi: 10.1161/JAHA.117.006402

104. Leong DP, Penhall A, Perry R, Shirazi M, Altman M, Chong D, et al. Speckle-tracking strain of the left atrium: a transoesophageal echocardiographic validation study. Eur Heart J Cardiovasc Imaging. (2013) 14:898-905. doi: 10.1093/ehjci/jes323

105. Pagola J, Juega J, Francisco-Pascual J, Bustamante A, Penalba A, Pala E, et al. Predicting atrial fibrillation with high risk of embolization with atrial strain and nT-proBNP. Transl Stroke Res. (2020). doi: 10.1007/s12975-02000873-2. [Epub ahead of print].

106. Leung M, van Rosendael PJ, Abou R, Ajmone Marsan N, Leung DY, Delgado $\mathrm{V}$, et al. Left atrial function to identify patients with atrial fibrillation at high risk of stroke: new insights from a large registry. Eur Heart J. (2018) 39:1416-25. doi: 10.1093/eurheartj/ehx736

107. Yaghi S, Liberman AL, Atalay M, Song C, Furie KL, Kamel H, et al. Cardiac magnetic resonance imaging: a new tool to identify cardioaortic sources in ischaemic stroke. J Neurol Neurosurg Psychiatry. (2017) 88:317. doi: 10.1136/jnnp-2016-314023

108. de Groot NM, Schalij MJ. Imaging modalities for measurements of left atrial volume in patients with atrial fibrillation: what do we choose? Europace. (2010) 12:766-7. doi: 10.1093/europace/euq140

109. Cochet H, Mouries A, Nivet H, Sacher F, Derval N, Denis A, et al. Age, atrial fibrillation, and structural heart disease are the main determinants of left atrial fibrosis detected by delayed-enhanced magnetic resonance imaging in a general cardiology population. J Cardiovasc Electrophysiol. (2015) 26:48492. doi: $10.1111 /$ jce.12651

110. Daccarett M, Badger TJ, Akoum N, Burgon NS, Mahnkopf C, Vergara G, et al. Association of left atrial fibrosis detected by delayed-enhancement magnetic resonance imaging and the risk of stroke in patients with atrial fibrillation. J Am Coll Cardiol. (2011) 57:831-8. doi: 10.1016/j.jacc.2010.09.049

111. King JB, Azadani PN, Suksaranjit P, Bress AP, Witt DM, Han FT, et al. Left atrial fibrosis and risk of cerebrovascular and cardiovascular events in patients with atrial fibrillation. J Am Coll Cardiol. (2017) 70:131121. doi: 10.1016/j.jacc.2017.07.758

112. Tandon K, Tirschwell D, Longstreth WT Jr, Smith B, Akoum N. Embolic stroke of undetermined source correlates to atrial fibrosis without atrial fibrillation. Neurology. (2019) 93:e381e7. doi: 10.1212/WNL.0000000000007827

113. Ntaios G, Pearce LA, Veltkamp R, Sharma M, Kasner SE, Korompoki E, et al. Potential embolic sources and outcomes in embolic stroke of undetermined source in the nAVIGATE-ESUS trial. Stroke. (2020) 51:1797804. doi: 10.1161/STROKEAHA.119.028669

114. Horstmann S, Rizos T, Güntner J, Hug A, Jenetzky E, Krumsdorf $\mathrm{U}$, et al. Does the sTAF score help detect paroxysmal atrial fibrillation in acute stroke patients? Eur J Neurol. (2013) 20:147-52. doi: 10.1111/j.1468-1331.2012.03816.x

115. Yoshioka K, Watanabe K, Zeniya S, Ito Y, Hizume M, Kanazawa T, et al. A score for predicting paroxysmal atrial fibrillation in acute stroke patients: iPAB score. J Stroke Cerebrovasc Dis. (2015) 24:22632269. doi: 10.1016/j.jstrokecerebrovasdis.2015.06.019

116. Figueiredo MM, Rodrigues AC, Alves MB, Neto MC, Silva GS. Score for atrial fibrillation detection in acute stroke and transient ischemic attack patients in a brazilian population: the acute stroke atrial fibrillation scoring system. Clinics (São Paulo). (2014) 69:241-6. doi: 10.6061/clinics/2014(04)04

Conflict of Interest: The authors declare that the research was conducted in the absence of any commercial or financial relationships that could be construed as a potential conflict of interest.

Copyright (C) 2021 Markus, Valerie and Mira. This is an open-access article distributed under the terms of the Creative Commons Attribution License (CC BY). The use, distribution or reproduction in other forums is permitted, provided the original author(s) and the copyright owner(s) are credited and that the original publication in this journal is cited, in accordance with accepted academic practice. No use, distribution or reproduction is permitted which does not comply with these terms. 